\title{
A NOTE
}

Africa is a verb to me.

The vitality that comes from the ground is an awakening.

The sunlight is special.

It is huge so dense it is like walking through concrete.

An artist, making the most ordinary thing,

sees at high intensity.

The texture of a simple country cloth expands in beauty.

A lovely market stool becomes a moment

of swift, tough abstract form.

The unrelenting sun allows no weakness.

A sculptor glides with it

as shadows and shining surfaces reveal themselves.

When a tool bites, the light decides.

A sculpture in a room sheds the memory of the sun.

It contains a sense of darkness, too-

the revelation of anti-light, as if condensed by enormous pressures.

The flicker of synapse between the sun and anti-light

is the action here.

This is why these objects are alive:

why they pour energy into the air;

why I stay in their fall-out.

\section{KATHERINE CORYTON WHTE}




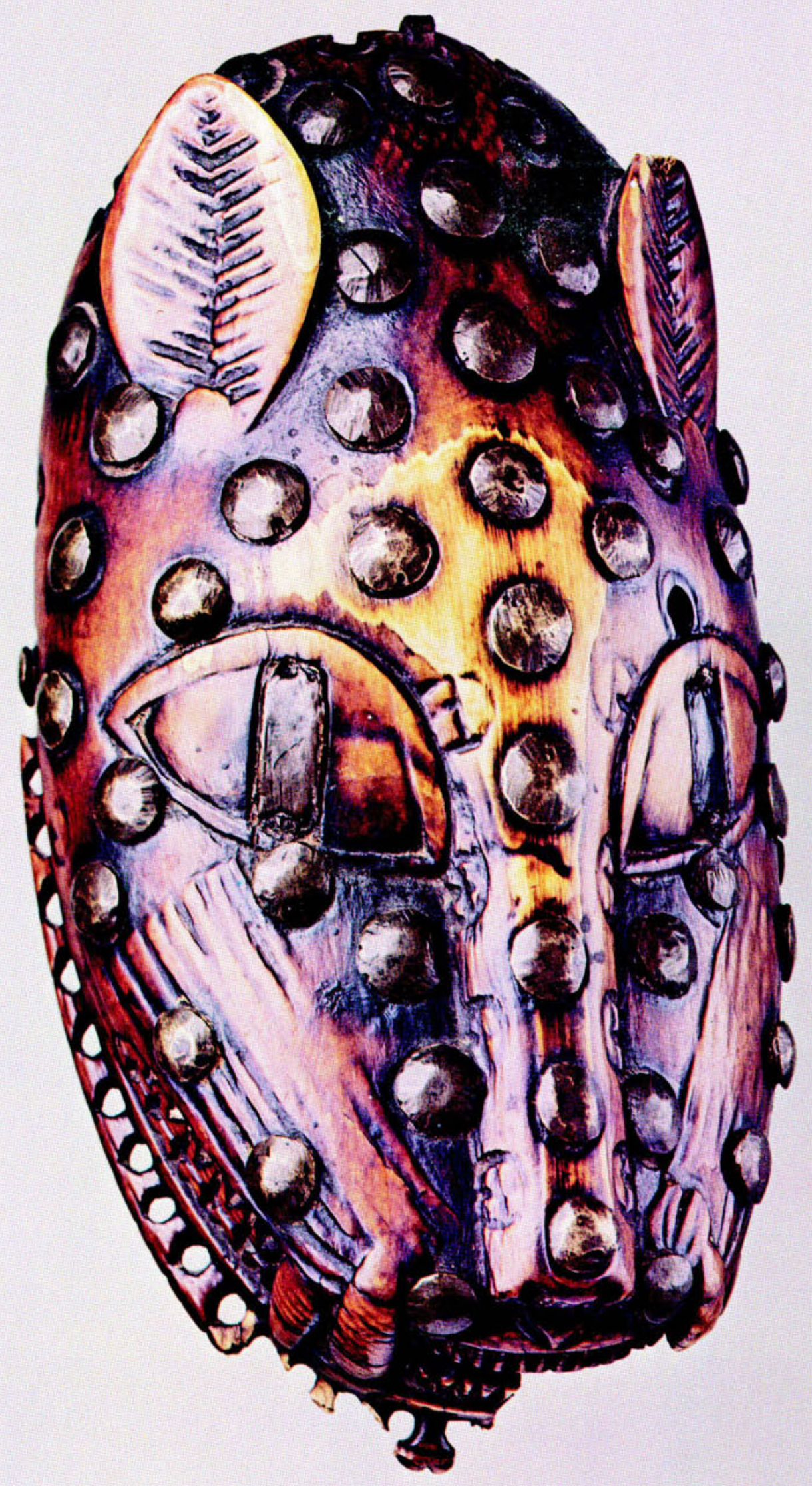

